\title{
Microsurgery can cure most intracranial dural arteriovenous fistulae of the sinus and non-sinus type
}

\author{
Dorothee Wachter • Franz Hans • \\ Marios-Nikos Psychogios • Michael Knauth • Veit Rohde
}

Received: 2 April 2010 /Revised: 7 January 2011 / Accepted: 28 January 2011 / Published online: 26 May 2011

(C) The Author(s) 2011. This article is published with open access at Springerlink.com

\begin{abstract}
There is consensus that intracranial dural arteriovenous fistulae (dAVF) with direct (non-sinus-type) or indirect (sinus-type) retrograde filling of a leptomeningeal vein should be treated due to the high risk of neurological deficits and hemorrhage. No consensus exists on treatment modality (surgery and/or embolization) and, if surgery is performed, on the best surgical strategy. This series aims to evaluate the role of surgery in the management of aggressive dAVFs. Forty-two patients underwent surgery. Opening and packing the sinus with thrombogenic material was performed in 9 of the 12 sinus-type dAVFs. In two sinus-type fistulae of the cavernous sinus and 1 of the torcular, microsurgery was used as prerequisite for subsequent embolization by providing access to the sinus. In the 30 non-sinus-type dAVFs, surgery consisted of interruption of the draining vein at the intradural entry point. In 41 patients undergoing 43 operations, elimination of the dAVF was achieved (97.6\%). In one case, a minimal venous drainage persisted after surgery. The transient surgical morbidity was $11.9 \%(n=5)$ and the permanent surgical morbidity $7.1 \%(n=3)$. Our surgical strategy was to focus
\end{abstract}

D. Wachter $(\triangle) \cdot$ V. Rohde

Department of Neurosurgery,

Georg-August-University Göttingen,

Robert-Koch-Strasse 40,

37075 Göttingen, Germany

e-mail: dorothee.wachter@gmx.de

F. Hans $\cdot$ V. Rohde

Department of Neurosurgery, University Hospital RWTH Aachen,

Aachen, Germany

M.-N. Psychogios $\cdot$ M. Knauth

Department of Neuroradiology, Georg-August-University

Göttingen,

Göttingen, Germany on the arterialized leptomeningeal vein in the non-sinustype and on the arterialized sinus segment in the sinus-type dAVFs allowing us to obliterate all but one dAVF with a low morbidity rate. We therefore propose that microsurgery should be considered early in the treatment of both types of aggressive dAVFs. In selected cases of cavernous sinus dAVFs, the role of microsurgery is reduced to that of an adjunct to endovascular therapy.

Keywords Intracranial dural arteriovenous fistulae $\cdot$ dAVF . Sinus-type fistula $\cdot$ Non-sinus-type fistula $\cdot$ Surgical strategies

\section{Introduction}

The aggressive type of intracranial dural arteriovenous fistulae (dAVF) with either direct (non-sinus-type dAVF) or indirect (sinus-type dAVF) retrograde filling of a leptomeningeal vein has a high propensity of ischemia, intracranial hypertension, and cerebral bleeding $[8,44]$. If left untreated, the mortality rate is $10.4 \%$, the annual bleeding and the nonhemorrhagic neurological deficit risks are $8.1 \%$ and $6.9 \%$, respectively. This leads to an annual event-rate of $15 \%$ [44]. Even benign dAVFs bear a risk of $2 \%$ to develop cortico-venous reflux with a subsequent risk of complications [33].

Therefore, consensus exists, that aggressive-type dAVFs should be treated $[2-4,6,8,10,17,22,24,46]$. However, dAVFs are rare vascular lesions and large institutional series published so far are seldom [8, 18]. This explains why no clear consensus exists on treatment modality (surgery and/or embolization) and, if surgery is performed, on the best surgical strategy $[7,8,12,16,18,22,23,26$, $28,32-35,37,40,44,46,48]$. After having treated 42 
dAVFs microsurgically, we feel encouraged to report our results and to present our surgical strategies.

\section{Materials and methods}

Study design

We retrospectively reviewed the medical records of patients with surgically managed dAVFs between 1990 and 2010 either at the department of neurosurgery at the University of Göttingen (2005-2010) or the University of Technology Aachen (1990-2004). The series is a consecutive surgical, but not un-biased series, because in five patients with sinustype fistulae and four patients with non-sinus-type fistulae embolization was initially attempted without success.

\section{Patients}

There were 42 patients ( 33 male, 9 female, median age of 58.4 years) with angiographically proven dAVFs (Table 1 ). Sinus fistulae (Fig. 1a and b) were found in 12 cases. The fistulae were located on the sigmoid/transverse sinus $(n=6)$, the superior sagittal sinus $(n=1)$, straight sinus $(n=1)$, cavernous sinus $(n=3)$, and superior petrous sinus $(n=1)$. There were 30 patients with non-sinus-type fistulae (Fig. 2a, b and c), with pure drainage into arterialized cortical veins, which were found at the convexity $(n=7)$, temporal $(n=3)$, posterior fossa/foramen magnum $(n=4)$, anterior fossa $(n=7)$ and tentorial $(n=9)$ as subsumed in

Table 1 Patient collective

\begin{tabular}{lll}
\hline Average age & Years & 58.4 \\
Min age & Years & 35 \\
Max age & Years & 72 \\
Gender $(N)$ & & \\
Female & 9 & $21.4 \%$ \\
Male & 33 & $78.6 \%$ \\
Sinus fistula $(n)$ & 12 & {$[28.6 \%]$} \\
Sigmoid/transverse sinus & 6 & $14.3 \%$ \\
Superior sagittal sinus & 1 & $2.4 \%$ \\
Straight sinus & 1 & $2.4 \%$ \\
Cavernous sinus & 3 & $7.1 \%$ \\
Superior petrous sinus & 1 & $2.4 \%$ \\
Non-sinus-fistula $(n)$ & 30 & {$[71.4 \%]$} \\
Convexity & 7 & $16.7 \%$ \\
Tentorial & 9 & $19.5 \%$ \\
Anterior fossa & 7 & $16.7 \%$ \\
Posterior fossa/for. magnum & 4 & $9.5 \%$ \\
Temporal & 3 & $7.1 \%$ \\
\hline
\end{tabular}
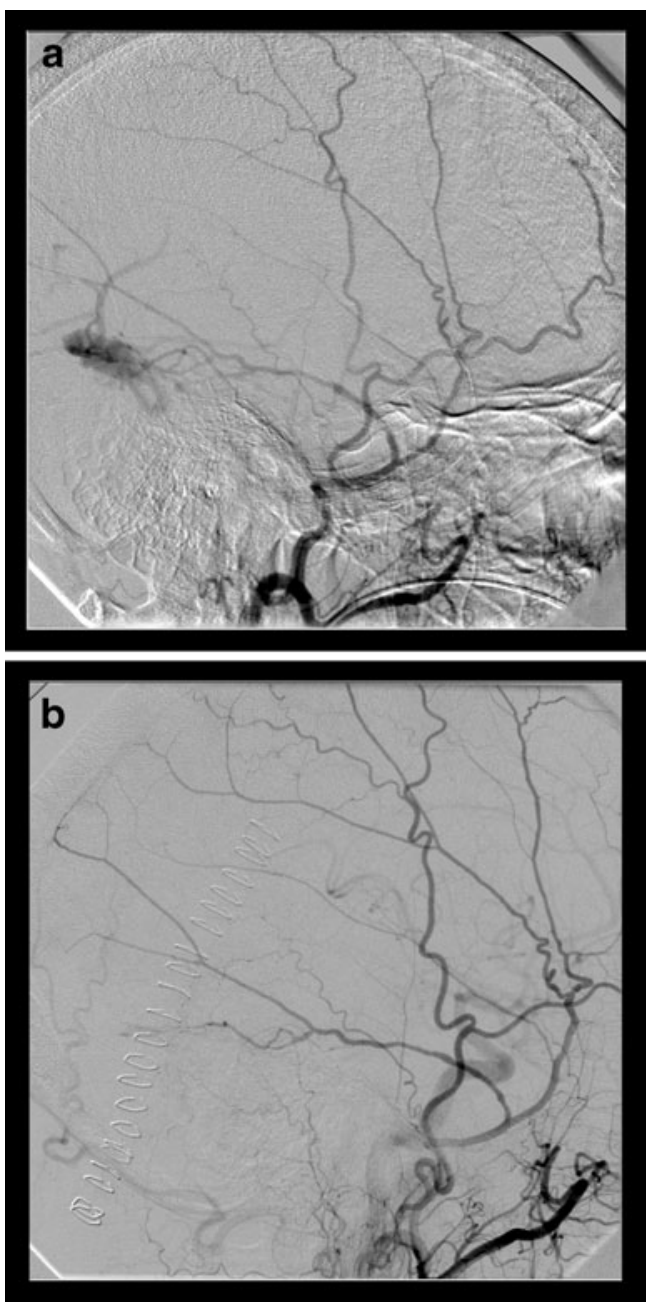

Fig. 1 a Preoperative angiographic finding of a sinus-type (sigmoid sinus) fistula. b Postoperative angiography demonstrating complete fistula occlusion after microsurgical sinus packing

Table 1. According to the angiographic criteria, 12 fistulae had been classified Borden type 2 and 30 fistulae Borden type 3 [4] according to the Borden Classification as described in Table 2.

\section{Clinical findings}

Clinical findings were epileptic seizures, pareses, aphasia or dysphasia, visual deficits, headache, gait disturbances, tinnitus, loss of consciousness, vertigo, dysmetria, apraxia, bulbous protrusion, and chemosis in 9 (21.4\%), 7 (16.7\%), 7 (16.7\%), 5 (9, 11), 6 (14.3\%), 5 (11.9\%), 3 (7.1\%), 3 (7.1\%), 2 (4.8\%), 2 (4.8\%), $2(4.8 \%), 2(4.8 \%)$ and $1(2.4 \%)$ cases, respectively (Table 3). Sixteen patients (40.5\%) suffered from intracerebral or subarachnoid hemorrhage. Multiple findings occurred in 12 patients (28.6\%). Fistulae were discovered incidentally in three asymptomatic patients $(7.1 \%)$ 
Fig. 2 a Preoperative angiographic finding of a non-sinus-type (temporal) fistula b: Three-dimensional reconstruction of CT angiography showing a non-sinus-type fistula: the images are suggestive of an occipital fistula with ectasies of arterialized leptomeningeal vein. Intraoperatively, those ectasies were found to be completely within the dural layers with the origin of the leptomeningeal vein in the anterior temporal fossa. c Postoperative angiography proving complete occlusion of the fistula following temporodorsal trephination and coagulation of the leptomeningeal vein
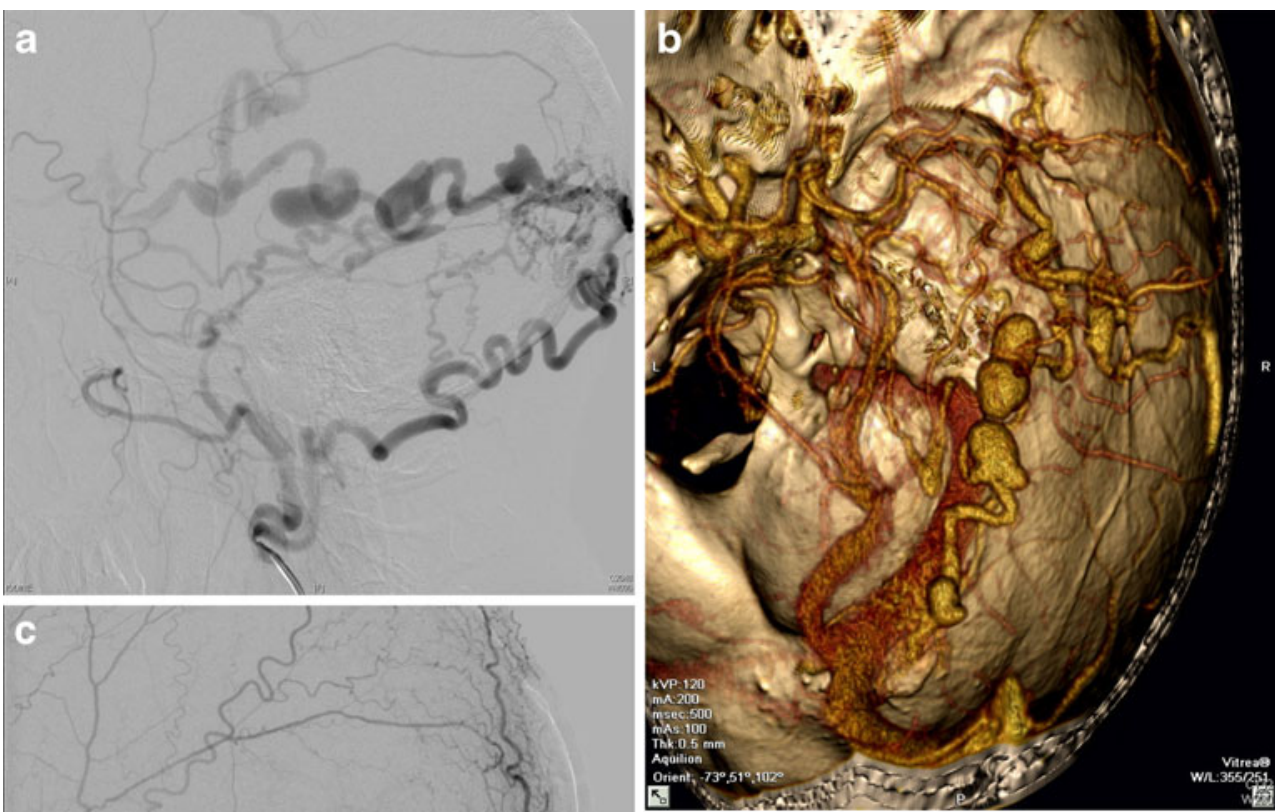

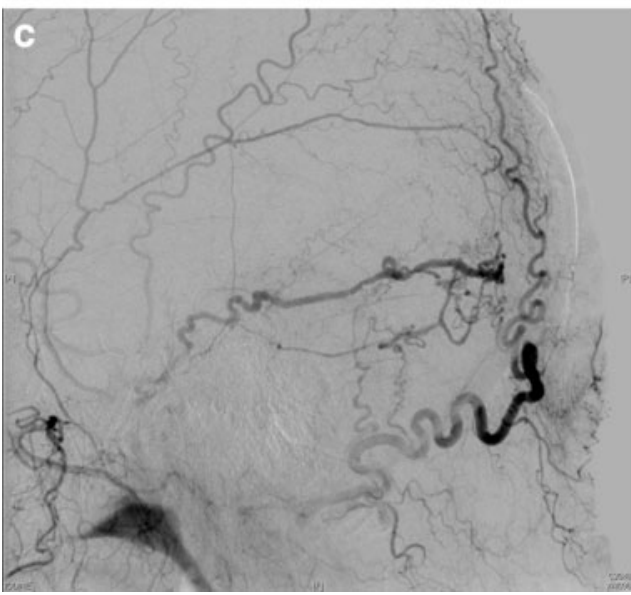

Follow-up investigations

Surgical strategy

In the non-sinus-type fistulae, the operative strategy consisted of sole interruption of the arterialized leptomeningeal vein, shortly after the dural entry/exit point, either by coagulation and cutting $(n=22)$ or by clipping $(n=8)$. No attempt was made to coagulate the feeding meningeal arteries or to excise the arterialized dura. In nine sinus-type fistulae with easily accessible sinus (transverse, sigmoid, superior sagittal sinus), the operative strategy consisted of exposure of the arterialized sinus segment, which then was packed with oxidized cellulose. No attempt was made to cut out the arterialized sinus segment in the last nine cases. In three sinus-type fistulae (one cavernous type and one straight sinus-type fistulae), the operative strategy was to provide access to the venous system for retrograde catheterization and embolization (Table 4). After surgery, angiography was performed in all patients either immediately after the operation or after recovery.
If postoperative angiography proved complete dAVF occlusion, patients were re-investigated yearly for at least 3 years clinically and radiologically using MRI and/or CT angiography and/or angiographic CT. In the absence of abnormal feeding arteries and/or arterialized draining veins and sinus segments, and stable or improving clinical status, no repeated angiography was performed. The follow-up time was 8 weeks to 10 years, with a mean of 4.2 years.

\section{Results}

In 39 cases $(92.9 \%)$, a total elimination of arteriovenous shunting could be achieved by the initial operation. In an extensive torcular/straight sinus and one ethmoidal dAVF, two operations were necessary for complete fistula occlusion. In two cases of sinus cavernous dAVFs, retrograde
Table 2 The Borden classification system
Borden Type I dAVF drainage into a dural venous sinus or meningeal vein with anterograde flow Borden Type II Anterograde drainage into dural venous sinus, retrograde flow occurs into cortical veins Borden Type III Direct retrograde flow of blood from the fistula into cortical veins 
Table 3 Neurological findings

\begin{tabular}{lrr}
\hline Presenting symptoms & & {$[\%]$} \\
\hline Intracranial hemorrhage/SAH & 16 & 38.1 \\
Seizure & 9 & 21.4 \\
Pareses & 7 & 16.7 \\
Aphasia or dysphasia & 7 & 16.7 \\
Visual deficits & 6 & 14.3 \\
Headache & 6 & 14.3 \\
Gait disturbances & 5 & 11.9 \\
Tinnitus & 3 & 7.1 \\
Loss of consciousness & 3 & 7.1 \\
Vertigo & 2 & 4.8 \\
Dysmetria & 2 & 4.8 \\
Apraxia & 2 & 4.8 \\
Bulbous protrusion & 2 & 4.8 \\
Chemosis & 1 & 2.4 \\
Incidental & 3 & 7.1 \\
\hline
\end{tabular}

embolization via the microsurgically opened venous pathway obliterated the fistula: in one patient, the superior ophthalmic vein was exposed microsurgically, in another patient, the initially inaccessible petrous sinus was opened by disconnecting the arterial outflow and, thereby, increasing the intracavernous pressure. In the third patient, with a cavernous sinus fistula, retrograde venous embolization via the petrous sinus and via the superior ophthalmic vein failed, and microsurgical cavernous sinus packing was successfully performed. In one case of a tentorial dAVF, a minimal venous drainage persisted after surgery. In total, the dAVF occlusion rate was $97.6 \%$ (Table 4).

Intra- and postoperative complications

Permanent, surgery-associated, neurological deficits were found in $3(7.1 \%)$ out of 42 patients (hyposmia, hemianopsia, and dysmetria in one case each). Transient morbidity occurred in five $(11.9 \%)$ patients. Pneumatocephalus in one patient and rebleeding in one patient required a second intervention without permanent neurological deficits. The rebleeding occurred in the only case of sinus-type fistulae, in which the arterialized sinus segment was resected. Cerebrospinal fluid (CSF) leakage developed in one patient, which was successfully managed by lumbar CSF drainage. In one case each, a transient paresis of the abducens or oculomotor nerve developed.

Follow-up investigations and outcome

After a mean follow-up period of 4.2 years, no re-opening of the initially occluded fistula, as indicated by the absence of arterialized cortical veins and/or sinus segments on MRI and/or CT, was seen. The minimal venous drainage after incomplete occlusion of a tentorial fistula, which was repeatedly followed by angiographies, remained unchanged during the follow-up period and was not re-treated so far. Fifteen of 16 patients, who experienced a subarachnoid or intracerebral hemorrhage, experienced incomplete recovery. Eight patients $(19.0 \%)$ with symptoms related to venous congestion showed an improvement of one or more preoperative clinical symptoms. Tinnitus and headache improved in two patients each $(4.8 \%)$. Five patients $(11.9 \%)$ were seizure-free after surgery.

\section{Discussion}

Dural arteriovenous fistulae are rarer than other intracranial vascular malformations. The development of dAVFs after sinus thrombosis, operation, and trauma involving the sinus had been described. Furthermore, animal experiments indicate that venous hypertension could induce dAVFs possibly mediated by vascular endothelial growth factor $[14,21,34,39]$. Thus, it is assumed by many that dAVFs are acquired lesions [7].

In 1990, Awad et al. performed a meta-analysis of 377 patients with cranial dAVFs previously presented in the medical literature. They concluded that the pattern of venous drainage is the primary determinant of aggressive behavior [2]. If the flow-through dAVFs empties into leptomeningeal veins either directly or via an arterialized sinus, it can cause venous tortuosity, variceal dilatation of pial veins, and local or regional intraparenchymal venous congestion which has a high propensity to result in nonhemorrhagic neurological deterioration, ischemia, intracranial hypertension, or cerebral bleeding [40]. Patients with aggressive dAVFs have an annual event-rate of $15 \%$ [44]. These data are confirmed by Singh et al. who analyzed 73 patients with intracranial bleeding out of 402 patients with dAVFs. They concluded that the bleeding risk, among others, rises with cortical venous drainage [35]. Independently from each other, Borden et al. and Cognard et al. proposed a classification of dAVFs based on the angiographic characteristics of non-aggressive and aggressive fistulae in 1995 [4, 7].

Consensus exists, that aggressive dAVFs should be treated to reduce the risk of bleeding and neurological deficits, but there is an ongoing discussion if microsurgery or endovascular obliteration or a combination of both offers the chance to eliminate the arterial flow in the leptomeningeal-draining vein. The rarity of dAVFs per se, the different angioarchitecture of sinus-type and nonsinus-type fistulae and the different fistula sites explain why no studies exist which compared microsurgery with endovascular therapy. 
Table 4 Summary of the angiographic findings and treatment strategies

\begin{tabular}{|c|c|c|c|c|c|c|}
\hline Patient no. & Type & Location & Approach & Treatment & Endovascular & Outcome angio \\
\hline 1 & ST & $\mathrm{SS} / \mathrm{TS}$ & RS & Packing with OS & & $\mathrm{CO}$ \\
\hline 2 & ST & $\mathrm{SS} / \mathrm{TS}$ & $\mathrm{RS}$ & Packing with OS & & $\mathrm{CO}$ \\
\hline 3 & ST & $\mathrm{SS} / \mathrm{TS}$ & RS & Packing with OS & & $\mathrm{CO}$ \\
\hline 4 & ST & $\mathrm{SS} / \mathrm{TS}$ & RS & Packing with OS & & $\mathrm{CO}$ \\
\hline 5 & ST & $\mathrm{SS} / \mathrm{TS}$ & SO & Packing with $\mathrm{M}$ & E transvenous & $\mathrm{CO}$ \\
\hline 6 & ST & $\mathrm{SS} / \mathrm{TS}$ & SO & Sinus Resection & E transvenous & $\mathrm{CO}$ \\
\hline 7 & ST & SSS & $\mathrm{OC} / \mathrm{SO}$ & Packing with OS & & $\mathrm{CO}$ \\
\hline 8 & ST & $\mathrm{CS}$ & Pterional & Cautery/division & E transvenous po & $\mathrm{CO}$ \\
\hline 9 & ST & $\mathrm{CS}$ & Pterional & $\mathrm{RCEaC}$ & E transvenous po & $\mathrm{CO}$ \\
\hline 10 & ST & $\mathrm{CS}$ & Pterional & Packing with OS & & $\mathrm{CO}$ \\
\hline 11 & ST & SPS & $\mathrm{OC} / \mathrm{SO}$ & Packing with OS & & $\mathrm{CO}$ \\
\hline 12 & ST & STRS & Parietal + SO & $\begin{array}{l}\text { 1. Packing with OS } \\
\text { 2. RCEaC }\end{array}$ & E transvenous po & $\mathrm{CO}$ \\
\hline 13 & NST & Convexity & Parietal & Clip ligation & & $\mathrm{CO}$ \\
\hline 14 & NST & Convexity & Parietal & Cautery/division & & $\mathrm{CO}$ \\
\hline 15 & NST & Convexity & Parietal & Cautery/division & & $\mathrm{CO}$ \\
\hline 16 & NST & Convexity & Parietal & Cautery/division & & $\mathrm{CO}$ \\
\hline 17 & NST & Convexity & Temporal & Cautery/division & & $\mathrm{CO}$ \\
\hline 18 & NST & Convexity & $\mathrm{OC}$ & Clip ligation & & $\mathrm{CO}$ \\
\hline 19 & NST & Convexity & Parieto-OC & Cautery/division & & $\mathrm{CO}$ \\
\hline 20 & NST & Anterior fossa & $\mathrm{IH}$ & Clip ligation & & $\mathrm{CO}$ \\
\hline 21 & NST & Anterior fossa & $\mathrm{IH}$ & Cautery/division & & $\mathrm{CO}$ \\
\hline 22 & NST & Anterior fossa & $\mathrm{IH}$ & Cautery/division & & $\mathrm{CO}$ \\
\hline 23 & NST & Anterior fossa & $\mathrm{IH}$ & Cautery/division & & $\mathrm{CO}$ \\
\hline 24 & NST & Anterior fossa & $\mathrm{IH}$ & Cautery/division & & $\mathrm{CO}$ \\
\hline 25 & NST & Anterior fossa & Frontobasal & Cautery/division & & $\mathrm{CO}$ \\
\hline 26 & NST & Anterior fossa & Frontobasal & Cautery/division & & $\mathrm{CO}$ \\
\hline 27 & NST & Tentorial & $\mathrm{S} / \mathrm{I}$ & Cautery/division & $\mathrm{E}$ arterial preop & $\mathrm{CO}$ \\
\hline 28 & NST & Tentorial & SO & Cautery/division & & Residual \\
\hline 29 & NST & Tentorial & SO & Clip ligation & & $\mathrm{CO}$ \\
\hline 30 & NST & Tentorial & $\mathrm{RM}$ & Clip ligation & & $\mathrm{CO}$ \\
\hline 31 & NST & Tentorial & Subtemporal & Cautery/division & E arterial preop & $\mathrm{CO}$ \\
\hline 32 & NST & Tentorial & $\mathrm{OC} / \mathrm{SO}$ & Cautery/division & & $\mathrm{CO}$ \\
\hline 33 & NST & Tentorial & $\mathrm{RM}$ & Clip ligation & & $\mathrm{CO}$ \\
\hline 34 & NST & Tentorial & SO & Cautery/division & & $\mathrm{CO}$ \\
\hline 35 & NST & Tentorial & SO & Cautery/division & E arterial preop & $\mathrm{CO}$ \\
\hline 36 & NST & $\mathrm{PF} / \mathrm{FM}$ & $\mathrm{RM}$ & Cautery/division & & $\mathrm{CO}$ \\
\hline 37 & NST & $\mathrm{PF} / \mathrm{FM}$ & FME & Clip ligation & & $\mathrm{CO}$ \\
\hline 38 & NST & $\mathrm{PF} / \mathrm{FM}$ & FME & Cautery/division & & $\mathrm{CO}$ \\
\hline 39 & NST & $\mathrm{PF} / \mathrm{FM}$ & SO & Cautery/division & & $\mathrm{CO}$ \\
\hline 40 & NST & Temporal & AS & Cautery/division & $\mathrm{E}$ arterial preop & $\mathrm{CO}$ \\
\hline 41 & NST & Temporal & Subtemporal & Clip ligation & & $\mathrm{CO}$ \\
\hline 42 & NST & Temporal & Temporal & Cautery/division & & $\mathrm{CO}$ \\
\hline
\end{tabular}

SS/TS sigmoid/transverse sinus, $S S S$ superior sagittal sinus, $S T R S$ straight sinus, $C S$ cavernous sinus, $S P S$ superior petrous sinus, $P F / F M$ posterior fossa/foramen magnum, $R M$ retromastoid approach, $S O$ suboccipital paramedian/median approach, $O C$ occipital approach, $I H$ interhemispheric approach, $S / I$ supracerebellar/infratentorial, $F M E$ foramen magnum enlargement, $A S$ anterosigmoid approach, $O S$ oxidized cellulose, $M$ muscle, po postoperative, $E$ embolization, $R C E a C$ retrograde coil-embolization after craniotomy 
Non-sinus-type fistulae

In non-sinus-type fistule, the institutional strategy was to interrupt the arterialized leptomeningeal vein, shortly after the dural entry/exit point without attacking the meningeal feeding arteries or excising the arterialized dura. Because these draining veins have inverted flow, the occlusion at their dural origin is not followed by further venous congestion [8, 16, 22, 40, 43, 45]. After occlusion, the draining vein thromboses without significant hemodynamical changes due to downstream veins that already have resumed the draining of functional cerebral areas. We achieved an overall occlusion rate of non-sinus-type fistulae in $97.6 \%$. The permanent surgery-associated morbidity rate for the whole series was $7.1 \%$, and for the non-sinus-type fistulae $4.8 \%(n=2)$. The induced neurological deficits could be considered to be minor. Neuronavigation, using CT angiographic data, proved to be helpful for intraoperative identification of the first segment of the leptomeningeal-draining vein [18]. An increasing number of publications support this concept and report comparable occlusion and morbidity rates $[8,16,18,22,40]$. Experiences with the endovascular management of nonsinus-type dAVFs likewise have been reported, but in many series the occlusion rate is lower and the complication rate higher [46]. With transarterial embolization, using particles or $\mathrm{N}$-butyl-2-cyanoacrylate occlusion rates between $28 \%$ and $33 \%$ could be achieved [40,43]. Better results were obtained by Agid et al., who achieved angiographic cure in $63.6 \%$ [1]. First experiences indicate that transarterial embolization with Onyx has the potential to yield higher occlusion rates. Jiang et al. report an occlusion rate of 68.4\% [47]. In the series of Carlson et al. and Nogueira et al., the occlusion rate was even higher with $80 \%$ and $83 \%$, respectively [5, 28]. Exceptionally good results were reported by Rossitti, who achieved a $100 \%$ occlusion rate [31]. Retrograde transvenous routes are rarely used in nonsinus-type fistulas due to the assumable high risk of rupture of the already fragile leptomeningeal-draining vein $[9,26$, 44]. Some combined transarterial and transvenous techniques. In a very recent paper, an occlusion rate of $96 \%$ had been reported in 25 patients [19]. However, it remained unclear if true non-sinus-type fistulas were treated in this series because an involvement of the sinus was described for all cases. Complication rates of $9 \%$, occasionally of up to $21 \%$, and even fatalities have been reported in contemporary endovascular series [19, 41, 45, 46, 48]. In consequence, we propose that microsurgical interruption of the draining vein should be the treatment of first choice in all patients with non-sinus-type dAVFs. This especially holds true because the leptomeningeal-draining vein is easily accessible by standard neurosurgical approaches in most instances [25]. The very recent papers of Rossitti and
Kirsch et al. indicate that advanced endovascular techniques yield results which are comparable to surgical results. Possibly, our proposal has to be re-evaluated with further up-coming endovascular series. Arterial embolization to mitigate blood loss during surgery is proposed by some $[18,30]$. However, in non-sinus-type fistulae we never experienced brisk bleeding during coagulation or clipping of the leptomeningeal vein, and therefore question the usefulness of preoperative arterial embolization.

\section{Sinus-type fistulae}

In sinus-type fistulae of sinuses, which are easily accessible by surgery (sigmoid/transverse sinus, superior sagittal sinus), our institutional strategy was to expose the arterialized segment of the sinus, to incise the wall minimally and to pack the sinus with oxidized cellulose until cessation of arterial blood flow. We achieved an overall occlusion rate of $100 \%$, without major morbidity and mortality, and a minor morbidity rate of $10 \%$. These results are in line with the few other surgical series $[10,17]$. In these surgical series, sinus packing was achieved with microcoils after sinus puncture. If sinus packing with coils is more advantageous than minimal sinus wall incision and packing with oxidized cellulose will remain a matter of discussion [17]. Possible arguments against sinus packing with coils are the higher costs and the need for intraoperative angiography or patient transfer [29, 30]. In the authors' opinion, there is rarely the need for microsurgical excision of the diseased sinus segment for control of the dAVF $[3,8$, 30]. Furthermore, excision of the arterialized sinus could lead to complications as reported in the literature and witnessed in one case of our series [38]. Van Dijk et al., who only disconnected the cortical venous reflux from the arterialized sinus, proposed a new surgical concept [44]. However, taken the assumed pathophysiology of sinus-type dAVFs, recruitment of new leptomeningeal veins seems possible [14, 39]. Furthermore, the assumption of van Dijk and co-workers that intradural disconnection of the arterialized cortical vein is less risky than sinus packing, which represents a completely extradural operation, could be challenged. In sinus-type fistulae, the retrograde transvenous embolization yields results, which are comparable to surgical sinus packing, with an obliteration rate of $81 \%$ to $87.5 \%$, and a permanent morbidity rate of $4 \%[19,32]$. Transarterial embolization with particles or glue often yields poorer results. Recently, transarterial embolization using Onyx has been proposed for the management of sinus-type fistulae [36]. The reported occlusion rate was $78 \%$. Another endovascular option is conversion of an aggressive into a non-aggressive fistula type by recanalization of the thrombosed sinus, but only single cases have been reported so far $[13,27]$. The comparable results of 
microsurgery and retrograde transvenous embolization do not allow the definition of the superior therapeutic option, but the lower invasiveness favors transvenous embolization as the first treatment option. However, microsurgery should be considered early if transvenous embolization fails.

Cavernous sinus dural arteriovenous fistulae

The cavernous sinus is not easily accessible by microsurgery and sinus packing is not without risk for the cranial nerves [42]. Furthermore, cavernous sinus fistulae could either be bilaterally fed from the carotid arteries or could extend to the contralateral side via the intercavernous sinus, making unilateral sinus packing often ineffective. Thus, cavernous sinus dAVFs are the domain of endovascular interventions [6]. In the rare cases in which the cavernous sinus cannot be reached transvenously, surgery is indicated to provide access to the cavernous sinus via the petrosal vein [15], or the superior ophthalmic vein [49] for retrograde catheterization. In one case, we disconnected the arterialized leptomeningeal-draining vein and thereby successfully increased the intracavernous pressure, which "opened" the blocked petrous sinus for successful retrograde embolization, which is a strategy that has not been reported so far. Very rarely, embolization proved to be not possible, as witnessed in one patient, and microsurgical sinus packing remains the only treatment option.

\section{Limitations of the study}

In many surgical and radiosurgical and some endovascular series, angiographic follow-up investigations in addition to early angiography after surgery were performed only sporadically or within less than 4 months [5, $16,18,20,22,31,42]$. Our study shares this limitation. From the scientific standpoint, repetitive follow-up angiography would be of interest to prove sustained occlusion of the fistula and to exclude distant fistula development. On the other hand, surgical series and recent endovascular series of transvenous embolization indicate that re-opening of the fistula is very rare after complete occlusion, which probably justifies that non-invasive imaging modalities such as MRI and CT angiography or, very recently, intravenous angiographic CT are used for follow-up imaging [12, 36, 44, 47].

\section{Other treatment options}

In 2005, Koebbe et al. described 18 cases of dAVF treatment either with gamma knife radiosurgery alone or in combination with embolization [20]. They achieved a total obliteration rate of $83.3 \%$. Friedman et al described their experiences with combined stereotactic radiosurgery and transarterial embolization for dAVFs of the transverse and sigmoid sinus. Although symptoms resolved or improved in $96 \%$ of the patients, $59 \%$ of the lesions were observed to persist to some degree on follow-up angiograms [11]. Apart of the comparatively low occlusion rate, it has to be taken into account that it takes months to years for thrombosis to occur, which is not acceptable if dealing with dAVFs of the aggressive type. At least if dealing with aggressive dAVFs, surgery and embolization remain the mainstays of the therapeutic management.

\section{Conclusion}

Our surgical strategy was to focus on the arterialized leptomeningeal vein in the non-sinus-type fistulae and on the arterialized sinus segment in the sinus-type fistulae. With this strategy, the operative morbidity is low and the dAVF occlusion rate is high in both non-sinus and sinustype fistulas. In the light of these results, we propose that microsurgery should be considered early in the management of aggressive cranial dAVFs. The only exceptions are selected cases of cavernous sinus dAVFs in which the role of surgery is not the elimination of the fistula, but the establishment of an access to the venous system for retrograde embolization.

Open Access This article is distributed under the terms of the Creative Commons Attribution Noncommercial License which permits any noncommercial use, distribution, and reproduction in any medium, provided the original author(s) and source are credited.

\section{References}

1. Agid R, Terbrugge K, Rodesch G, Andersson T, Söderman M (2009) Management strategies for anterior cranial fossa (ethmoidal) dural arteriovenous fistulas with an emphasis on endovascular treatment. J Neurosurg 110:79-84

2. Awad IA, Little JR, Akarawi WP, Ahl J (1990) Intracranial dural arteriovenous malformations: factors, predisposing to an aggressive neurological course. J Neurosurg 72:839-850

3. Barnwell SL, Halbach VV, Dowd CF, Higashida RT, Hieshima GB, Wilson CB (1989) Complex dural arteriovenous fistulas. J Neurosurg 71:352-358

4. Borden JA, Wu JK, Shucart WA (1995) A proposed classification for spinal and cranial dural arteriovenous fistulous malformations and implications for treatment. J Neurosurg 82:166-179

5. Carlson AP, Taylor CL, Yonas H (2007) Treatment of dural arteriovenous fistula using ethylene vinyl alcohol (Onyx) arterial embolization as the primary modality: short-term results. J Neurosurg 107:1120-1125

6. Cheng KM, Chan CM, Cheung YL (2003) Transvenous embolisation of dural carotid cavernous fistulas by multiple venous routes: a series of 27 cases. Acta Neurochir Wien $145: 17-29$ 
7. Cognard C, Gobin YP, Pierot L, Bailly AL, Houdart E, Casasco A, Chiras J, Merland JJ (1995) Cerebral dural arteriovenous fistulas: clinical and angiographic correlation with a revised classification of venous drainage. Radiology 194:671-680

8. Collice M, D'Alberti G, Arena O, Solaini C, Fontana RA, Talamonti G (2000) Surgical treatment of intracranial dural arteriovenous fistulae: role of venous drainage. Neurosurgery 47:56-67

9. Deasy NP, Gholkar AR, Cox TC, Jeffree MA (1999) Tentorial dural arteriovenous fistulae: endovascular treatment with transvenous coil embolisation. Neuroradiology 41:308-312

10. Endo S, Kuwayama N, Takaku A, Nishijima M (1998) Direct packing of the isolated sinus in patients with dural arteriovenous fistulas of the transverse-sigmoid sinus. J Neurosurg 88:449-456

11. Friedman JA, Pollock BE, Nichols DA, Gorman DA, Foote RL, Stafford SL (2001) Results of combined stereotactic radiosurgery and transarterial embolization for dural arteriovenous fistulas of the transverse and sigmoid sinuses. J Neurosurg 94:886-891

12. Goto K, Sidipratomo P, Ogata N, Inoue T, Matsuno H (1999) Combining endovascular and neurosurgical treatments of highrisk dural arteriovenous fistulas in the lateral sinus and the confluence of the sinuses. J Neurosurg 90:289-299

13. Gutierrez A, Do HM, Marks MP (2004) Alteration in the venous drainage of a dural arteriovenous fistula following angioplasty. AJNR 25:1086-1088

14. Hamada Y, Goto K, Inoue T, Iwaki T, Matsuno H, Suzuki S, Matsushima T, Fukui M, Miyake E (1997) Histopathological aspects of dural arteriovenous fistulas in the transverse-sigmoid sinus region in nine patients. Neurosurgery 40:452-456

15. Hara T, Hamada J, Kai Y, Ushio Y (2002) Surgical transvenous embolization of a carotid-cavernous dural fistula with cortical drainage via a petrosal vein: two technical case reports. Neurosurgery 50:1380-1384

16. Hoh BL, Choudhri TF, Connolly ES Jr, Solomon RA (1998) Surgical management of high-grade intracranial dural arteriovenous fistulas: leptomeningeal venous disruption without nidus excision. Neurosurgery 42:796-805

17. Houdart E, Saint-Maurice JP, Chapot R, Ditchfield A, Blanquet A, Lot G, Merland JJ (2002) Transcranial approach for venous embolization of dural arteriovenous fistulas. J Neurosurg 97:280-286

18. Kakarla UK, Deshmukh VR, Zabramski JM, Albuquerque FC, McDougall CG, Spetzler RF (2007) Surgical treatment of highrisk intracranial dural arteriovenous fistulae: clinical outcome and avoidance of complications. Neurosurgery 61:447-459

19. Kirsch M, Liebig T, Kühne D, Henkes H (2009) Endovascular management of dural arteriovenous fistulas of the transverse and sigmoid sinus in 150 patients. Neuroradiology 51:477-483

20. Koebbe CJ, Singhal D, Sheehan J, Flickinger JC, Horowitz M, Kondziolka D, Lunsford LD (2005) Radiosurgery for dural arteriovenous fistulas. Surg Neurol 64:392-399

21. Lawton MT, Jacobowitz R, Spetzler RF (1997) Redifined role of angiogenesis in the pathogenesis of dural arteriovenous malformations. J Neurosurg 87:267-274

22. Lawton MT, Sanchez-Mejia RO, Pham D, Tan J, Halbach VV (2008) Tentorial dural arteriovenous fistulae: operative strategies and microsurgical results for six types. Neurosurgery 62:ONS110ONS125

23. Liu JK, Dogan A, Ellegala DB, Carlson J, Nesbit GM, Barnwell SL, Delashaw JB (2009) The role of surgery for high-grade intracranial dural arteriovenous fistulas: importance of obliteration of venous outflow. J Neurosurg 110:913-920

24. Lucas CP, Zabramski JM, Spetzler RF, Jacobowitz R (1997) Treatment for intracranial dural arteriovenous malformations: a meta-analysis from the English language literature. Neurosurgery 40:1119-1132
25. Mayfrank L, Reul J, Huffmann B, Bertalanffy H, Spetzger U, Gilsbach JM (1999) Microsurgical interhemispheric approach to dural arteriovenous fistulas of the floor of the anterior cranial fossa. Minim Invasive Neurosurg 39:74-77

26. Mironov A (1998) Elective transvenous embolization of dural fistulas without occlusion of the dural sinus. AJNR 19:389-391

27. Murphy KJ, Gailloud P, Venbrux A, Deramond H, Hanley D, Rigamonti D (2000) Endovascular treatment of a grade IV transverse sinus dural arteriovenous fistula by sinus recanalization angioplasty, and stent placement: technical case report. Neurosurgery $46: 497-500$

28. Nogueira RG, Dabus G, Rabinov JD, Eskey CJ, Ogilvy CS, Hirsch JA, Pryor JC (2008) Preliminary experience with Onyx embolization for the treatment of intracranial dural arteriovenous fistulas. AJNR 29:91-97

29. Pierot L, Visot A, Boulin A, Dupuy M (1998) Combined neurosurgical and neuroradiological treatment of a complex superior sagittal sinus dural fistula: technical note. Neurosurgery 42:194-197

30. Rath SA, Derakshani S (2004) Concepts of combined endovascular and surgical treatment for dural arteriovenous fistulae: concepts derived from experience in treating three unusual lesions. Acta Neurochir Wien 146:229-235

31. Rossitti S (2009) Transarterial embolization of intracranial dural arteriovenous fistulas with direct cortical venous drainage using ethylene vinyl alcohol copolymer (Onyx). Clin Neuroradiol 19:122-128

32. Roy D, Raymond J (1997) The role of transvenous embolization in the treatment of intracranial dural arteriovenous fistulas. Neurosurgery 40:1133-1144

33. Satomi J, van Dijk MC, TerBrugge RG, Willinsky RA, Wallace MC (2002) Benign cranial dural arteriovenous fistulas: outcome of conservative management based on the natural history of the lesion. J Neurosurg 97:767-770

34. Shin Y, Nakase H, Nakamura M, Shimada K, Konishi N, Sakaki T (2007) Expression of angiogenetic growth factor in the rat dAVF model. Neurol Res 29:727-733

35. Singh V, Smith WS, Lawton MT, Halbach VV, Young WL (2008) Risk factors for hemorrhagic presentation in patients with dural arteriovenous fistulae. Neurosurgery 62:628-635

36. Stiefel MF, Albuquerque FC, Park MS, Dashti SR, McDougall CG (2009) Endovascular treatment of intracranial dural arteriovenous fistulae using Onyx: A case series. Neurosurgery 65(6 Suppl):132-139

37. Strom RG, Botros JA, Refai D, Moran CJ, Cross DT 3rd, Chicoine MR, Grubb RL Jr, Rich KM, Dacey RG Jr, Derdeyn CP, Zipfel GJ (2009) Cranial dural arteriovenous fistulae: asymptomatic cortical venous drainage portends less aggressive clinical course. Neurosurgery 64:241-247

38. Sundt TM Jr, Piepgras DG (1983) The surgical approach to arteriovenous malformations of the lateral and sigmoid dural sinuses. J Neurosurg 59:32-39

39. Terada T, Higashida RT, Halbach VV, Dowd CF, Tsuura M, Komai N, Wilson CB, Hieshima GB (1994) Development of acquired arteriovenous fistulas in rats due to venous hypertension. J Neurosurg 80:884-889

40. Thompson BG, Doppman JL, Oldfield EH (1994) Treatment of cranial dural arteriovenous fistulae by interruption of leptomeningeal venous drainage. J Neurosurg 80:617-623

41. Tomak PR, Cloft HJ, Kaga A, Cawley CM, Dion J, Barrow DL (2003) Evolution of the management of tentorial dural arteriovenous malformations. Neurosurgery 52:750-762

42. Tu YK, Liu HM, Hu SC (1997) Direct surgery of carotid cavernous fistulae and dural arteriovenous malformations of the cavernous sinus. Neurosurgery 41:798-805 
43. Ushikoshi S, Houkin K, Kuroda S, Asano T, Iwasaki Y, Miyasaka $\mathrm{K}$, Abe H (2002) Surgical treatment of intracranial dural arteriovenous fistulas. Surg Neurol 57:253-261

44. van Dijk JM, TerBrugge KG, Willinsky RA, Wallace MC (2004) Clinical course of cranial dural arteriovenous fistulas with longterm persistent cortical venous reflux. Stroke 33:1233-1236

45. van Lindert E, Hassler W, Kühne D, Henkes H (2000) Combined endovascular-microsurgical treatment of tentorial-incisural dural arteriovenous malformations. Report of five cases. Minim Invas Neurosurg 43:138-143

46. van Rooij WJ, Sluzewski M, Beute GN (2007) Dural arteriovenous fistulas with cortical venous drainage: incidence, clinical presentation, and treatment. AJNR 28:651-655

47. Wachter D, Psychogios M, Knauth M, Rohde V (2010) IvACT after aneurysm clipping as an alternative to digital subtraction angiography first experiences. Cen Eur Neurosurg 71:121-125

48. Yiang C, Lv X, Li Y, Zhang J, Wu Z (2009) Endovascular treatment of high-risk tentorial dural arteriovenous fistulas: clinical outcomes. Neuroradiology 51:103-111

49. Yu SCH, Cheng HKM, Wong GKC, Chan CM, Cheung JYL, Poon WS (2007) Transvenous embolization of dural carotidcavernous fistulae with transfacial catheterization through the superior ophthalmic vein. Neurosurgery 60:1032-1038

\section{Comments}

Nicholas C. Bambakidis, Cleveland, USA

This paper reports on a large series of dural AVFs, all of which were treated surgically. The authors point out accurately that no direct comparison studies are available between surgical treatment and endovascular management of these lesions. This is a nice review and is timely. Advancing technology has made endovascular treatment of such lesions increasingly possible. In particular, the "sinus-type" of dAVFs are generally quite amenable to endovascular treatment, and though the authors note a good success rate with open surgical treatment, only 12 such cases are described. In fact, the endovascular literature regarding transvenous embolization is quite impressive and, in my opinion, surgical management of these lesions is rarely necessary. This paper should not be taken to reflect the opinion that dAVFs involving the sinus should be treated surgically as a primary option, and in fact the authors note that the less invasive nature of endovascular treatment favors it as the primary modality in the majority of cases.

Additionally, the authors nicely review the literature for "non-sinus type" dAVFs, which are primarily surgical lesions easily treated by primary obliteration of the fistula by interrupting venous outflow.

William T. Couldwell, Steven Stevens, Salt Lake City, USA

The authors have reviewed the treatment and outcomes of 42 patients with dural arteriovenous fistulas (AVFs) at their institutions over a 20-year period (1990-2010). They note that of the 42 patients, 12 had the sinus-type of fistula while 30 had the non-sinus type. The majority ( 30 patients) had the higher Borden angiographic grade (II or III) indicating increased risk of intracranial hemorrhage from retrograde cortical venous drainage. In this regard, $40 \%$ of the patients had suffered an intracerebral or subarachnoid hemorrhage prior to treatment.
In the non-sinus type of fistulas, the technique of subarachnoid vein interruption was used (clipped or coagulated). For the sinus-type dAVFs, the technique employed was to pack the arterialized sinus with oxidized cellulose (nine cases) to provide transvenous access to the fistula for endovascular obliteration (three cases). At a mean follow-up period of 42 months, there was no recanalization of fistula in those that were initially obliterated; and, in the one patient with partial treatment, there was no clinical or radiographic progression during follow-up. The authors should be commended on their successful treatment of this difficult group of patients.

The experience of the authors represents the best example of the surgical ability to repair the dAVF. Admittedly, the authors have imperfect follow-up as late angiography was not obtained in many patients. Our recent experience with endovascular techniques indicates that in the majority of patients, this would be our first option.

The authors note the recent introduction of Onyx, a liquid embolic agent consisting of an EtOH copolymer suspended in DMSO and using tantalum powder as a contrast agent, as an embolic agent for the treatment of both direct and indirect arteriovenous fistulas. With incremental experience with Onyx, new delivery techniques have improved the distal penetration and safer control of the material. The use of the "plug and push", the dual catheters in separate territories, the tandem dual catheters in a single feeder and the use of balloon assist for direction control have all resulted in safer and improved rates of complete AVF cure.

Although the number of reported cases treated with these newer techniques is small, the success rates are rapidly improving. The advantage of endovascular treatment is the immediate confirmation of occlusion and the decreased length of hospital stay. The disadvantage is the increased radiation exposure during prolonged injection. This can be somewhat mitigated by the use of lower frame rates during the injection process and the careful attention to radiation safety principles.

\section{Basant Misra, Mumbai, India}

The authors report their experience with microsurgical treatment of 42 aggressive (Borden Types II and III) dural arteriovenous fistulas (dAVFs) over a 20-year period. There were 30 non-sinus-type and 12 sinus-type fistulas. Microsurgical interruption of arterialized vein was the sole treatment in the non-sinus-type fistula. Complete obliteration of the dAVF was achieved in all but one case of this type. In the sinus type, packing of the sinus was done with successful obliteration of the dAVF in 9 out of 12. In the remaining three, the microsurgical strategy was to provide access for retrograde catheterization and embolization. Overall, the dAVF occlusion rate was a remarkable 97.6\%. Permanent neurological deficit attributable to surgery was found in only $7.1 \%$ cases. The authors have to be congratulated for the excellent results achieved in their series of dAVF treated microsurgically. The strategy employed is simple and definitely economical compared to endovascular treatment. However, one of the major limitations of this study is lack of long-term follow-up angiographic data.

Endovascular treatment has been the first line of treatment in our department for most aggressive dural AVF. We do occasionally resort to microsurgery as the primary treatment for the non-sinus-type dAVF. One of the problems, in our experience, is the presence of multiple arterialized veins and difficulty in choosing the critical communication to be interrupted. Our recent experience with ICG dye videoangiography has been quite encouraging in defining and sacrificing the retrograde arterialized draining vein. 